\title{
Giant inflammatory fibroid polyp of ileum causing intussusception: a case report

\author{
Sami Akbulut ${ }^{1}$, Mert Mahsuni Sevinc ${ }^{1}$, Bahri Cakabay ${ }^{1}$, Sule Bakir $^{2}$ \\ and Ayhan Senol ${ }^{3}$
}

\begin{abstract}
Addresses: ${ }^{1}$ Department of Surgery, Diyarbakir Education and Research Hospital, Diyarbakir 21400, Turkey
${ }^{2}$ Department of Pathology, Diyarbakir Education and Research Hospital, Diyarbakir 21400, Turkey

${ }^{3}$ Department of Radiology, Diyarbakir Education and Research Hospital, Diyarbakir 21400, Turkey
\end{abstract}

Email: SA* - akbulutsami@gmail.com; MMS - mahsunisevinc@yahoo.co.uk; BC - surgeonbahri@gmail.com; SB - sulebakir09@hotmail.com; AS - ayhansenol@hotmail.com

* Corresponding author

Received: 14 July 2009 Accepted: 3 August 2009 Published: 12 August 2009

Cases Journal 2009, 2:8616 doi: 10.4076/1757-1626-2-8616

This article is available from: http://casesjournal.com/casesjournal/article/view/8616

(C) 2009 Akbulut et al.; licensee Cases Network Ltd.

This is an Open Access article distributed under the terms of the Creative Commons Attribution License (http://creativecommons.org/licenses/by/3.0), which permits unrestricted use, distribution, and reproduction in any medium, provided the original work is properly cited.

\begin{abstract}
Inflammatory fibroid polyps are rare, localized, non-neoplastic lesions originating in the submucosa of the gastrointestinal tract. Intussusception due to inflammatory fibroid polyps is uncommon; moreover, ileo-ileal intussusception has only rarely been reported. Here, we report an $1 \mathrm{I} \times 7 \mathrm{~cm}$ giant inflammatory fibroid polyp of the small bowel that presented as intussusception in a 73-year-old woman. Ultrasonography demonstrated a solid, homogeneous, echogenic mass surrounded by the typical mural layers of an invaginated ileum. The immunohistopathological diagnosis after segmental ileal resection was an ileal inflammatory fibroid polyp. Although encountered rarely in adults, physicians should be aware of invagination and consider it in each case of acute abdomen because of the wide spectrum of clinical settings.
\end{abstract}

\section{Introduction}

Intussusception occurs when a more proximal portion of bowel invaginates into more distal bowel [1]. Adult intussusception is relatively rare, constituting only $1 \%$ of patients with bowel obstructions [2]. The cause of intussusception in children differs from that in adults. Adult invagination is mostly caused by tumors [3] and $80 \%$ of the tumors associated with small bowel intussusception are benign $[3,4]$. Lipoma is the most common benign tumor in intussusception. Inflammatory fibroid polyps (IFP) rarely cause ileal intussusception. Here, we report an unusual case of ileo-ileal intussusception caused by an IFP. In addition, this is the third largest IFP reported in the English literature $[5,6]$.

\section{Case presentation}

A 73-year-old Turkish woman was admitted to our emergency unit suffering from abdominal pain, nausea and vomiting, constipation, no passage of gas or feces, and abdominal distension for 5 days. Laboratory investigations showed the following: blood urea nitrogen, $27 \mathrm{mg} / \mathrm{dl}$; creatinine, $0.9 \mathrm{mg} / \mathrm{dl}$; and C-reactive protein, $72 \mathrm{mg} / \mathrm{L}$. The blood cell count revealed leukocytosis at $18,000 / \mu l$,

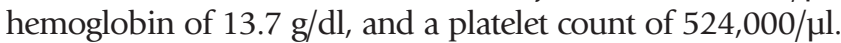


Other serum parameters were within normal limits. The physical examination revealed muscular guarding and rebound tenderness in the periumbilical region. An upright plain abdominal film revealed small bowel obstruction with marked small bowel air-fluid levels. Abdominal ultrasound revealed a target lesion in a small bowel segment, indicating intussusception (Figure 1). The patient underwent an emergency laparotomy via a midline incision. On exploration, an ileo-ileal intussusception was found $100 \mathrm{~cm}$ proximal to the ileocecal valve. The intussuscepted intestinal segments were obstructing the lumen, causing dilatation in the intestine proximal to the intussusception (Figure 2 and Figure 3). We performed a segmental small bowel resection and an end-to-end anastomosis. The patient had an uneventful postoperative course and was discharged on the sixth postoperative day. The pathology examination showed an $11 \times 7 \mathrm{~cm}$ inflammatory fibroid polyp composed of an edematous stroma containing spindle-shaped stromal cells, lymphoid nodules, and eosinophils.

\section{Discussion}

Intussusception develops due to a difference in motility between two intestinal parts. One segment (the intussusceptum) enters a neighboring one (the intussusceptiens) [7]. Barbette of Amsterdam first reported intussusception in 1674 [8]. Malignant or benign lesions, usually appearing at the head of the invagination, cause $65 \%$ of all adult

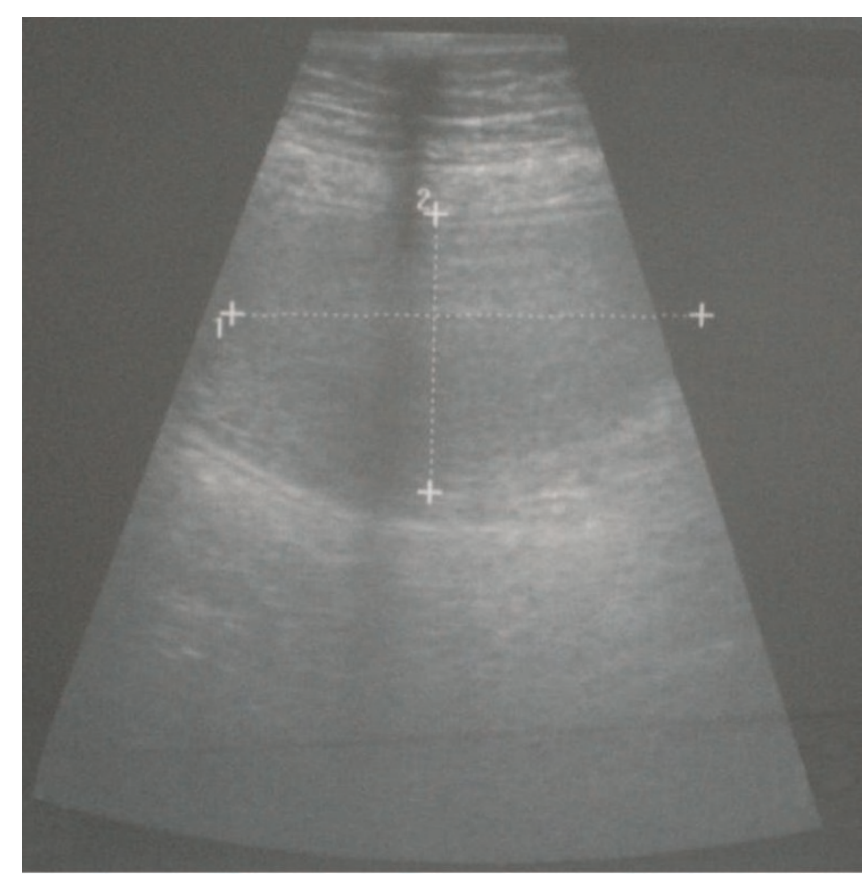

Figure I. Ultrasound examination: a transverse section of an ileal loop shows an echogenic $7-\mathrm{cm}$ intraluminal mass.

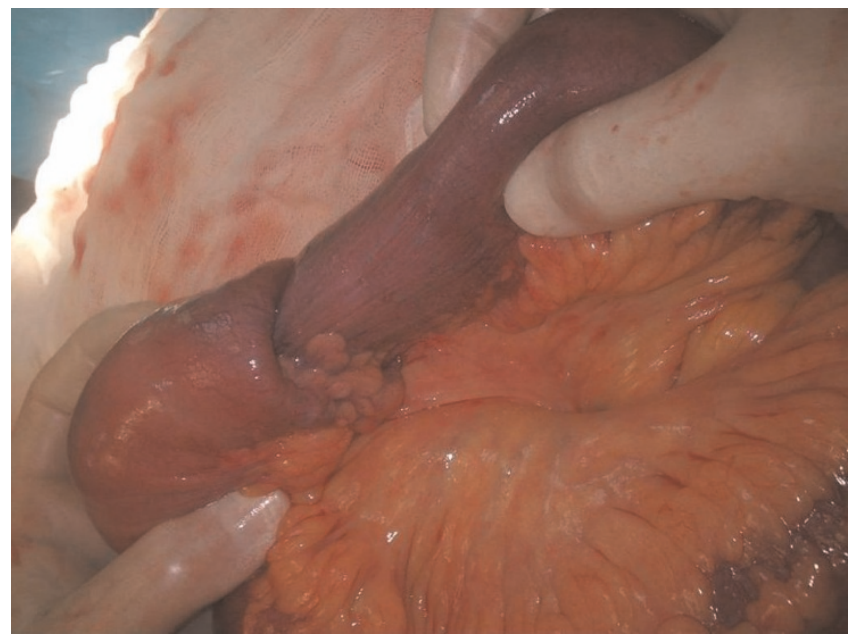

Figure 2. The view of the invaginated segments.

intussusceptions. Malignant lesions are found in $14 \sim 47 \%$ of cases occurring in the small intestine. Benign tumors as the lead points of an intussusception include lipomas, leiomyomas, neurofibromas, adenomas, and inflammatory fibroid polyps [9].

Inflammatory fibroid polyps are rare, benign, tumor-like lesions of the gastrointestinal tract. The lesion was first described by Vanek in 1949. Most frequently, they are localized in the gastric antrum, but can develop anywhere in the gastrointestinal tract. In the small intestine, the ileum is the most common site where these polyps cause intussusception. An IFP is a benign reactive lesion that occurs predominantly in adults. Most IFPs are polypoid masses smaller than $5 \mathrm{~cm}$, although sizes up to $20 \mathrm{~cm}$ have

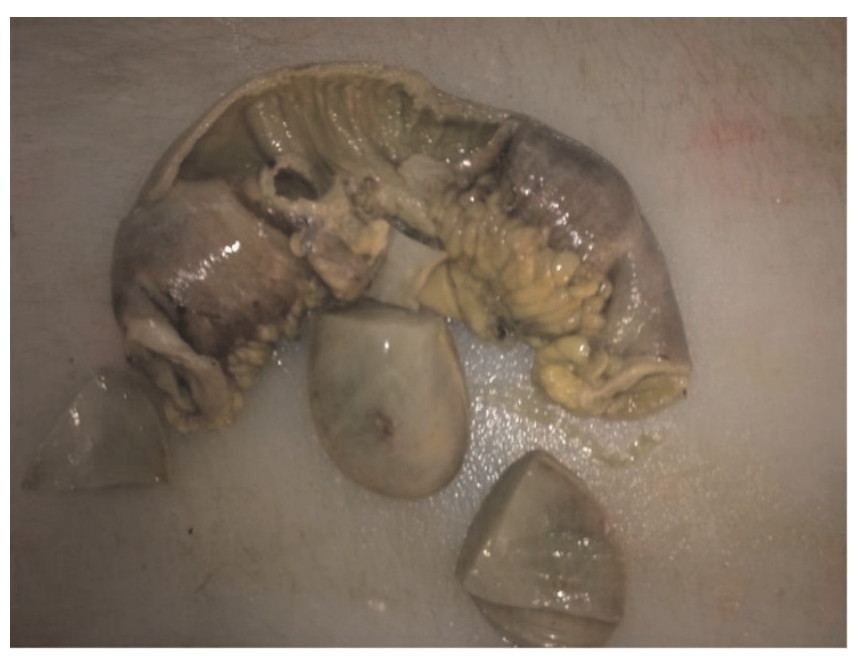

Figure 3. The resected ileal segments with the polyp. 
been reported [10-12]. In the literature, the average age of intussusception in adults is $38.6 \sim 57.5$ years. The gender distribution is roughly equal [13]. To our knowledge, our patient is the second oldest to develop invagination due to an IFP [14].

A preoperative diagnosis of intussusception is rare, but can be made on finding a palpable mass in the abdomen or with the use of imaging techniques [15]. The primary imaging modality of choice is ultrasound scanning, which enables the diagnosis or exclusion of intussusception with a sensitivity of $98 \sim 100 \%$, specificity of $88 \%$, and negative predictive value of $100 \%$ [16]. The majority of intussusceptions are diagnosed at surgery. In our case, the preoperative clinical findings and ultrasonic images suggested invagination. The ultrasound images of the small bowel lumen showed a solid mass $7 \mathrm{~cm}$ in diameter. The clinical presentation in adult intussusception is often chronic, and most patients present with non-specific symptoms that are suggestive of intestinal obstruction. Abdominal pain is the most common symptom, followed by vomiting and nausea [7]. The optimal management of adult intussusception remains controversial. Exploratory laparotomy is frequently recommended as a treatment for fibroid polyps. The lesion seems to lack malignant potential and recurrence of the polyp has been reported only once [7]. Our patient has had no recurrence after follow-up for 18 months.

Morphologically, IFPs can mimic several other tumor and non-tumor processes of the gastrointestinal tract, including inflammatory myofibroblastic tumors, eosinophilic gastroenteritis, gastrointestinal stromal tumors (GISTs), and other mesenchymal lesions. Sometimes differentiation is difficult, especially differentiation between inflammatory fibroid polyps and GIST [12]. In our case, the immunohistochemical examination showed spindleshaped cells in the circumference of small blood vessels expressing vimentin, but not CD34, CD117, or SMA.

In conclusion, the recommended treatment of adult intestinal invagination is surgical resection of the intestinal segments involved. This case report demonstrates that intussusception, although rare in adults, should be considered in the differential diagnosis of abdominal pain.

\section{Abbreviations}

GIST, gastrointestinal stromal tumor; IFP, inflammatory fibroid polyps.

\section{Consent}

Written informed consent was obtained from the patient for publication of this case report and accompanying image. A copy of the written consent is available for review by the Editor-in-Chief of this journal.

\section{Competing interests}

The authors declare that they have no competing interests.

\section{Author's contributions}

SA and MM performed surgical procedure. SA and BC contributed writing the article and review of the literature as well as undertaking a comprehensive literature search. SA and MM contributed design and manuscript preparation. AS provided the radiological information. SB provided the pathological information.

\section{References}

I. Waseem M, Rosenberg HK: Intussusception. Pediatr Emerg Care 2008, 24:793-800.

2. Stewart D, Hughes M, Hope WW: Laparoscopic-assisted small bowel resection for treatment of adult small bowel intussusception: a case report. Cases / 2008, I:432.

3. Tekin A, Aksoy F, Vatansev C, Kücükkartallar T, Belviranli M, Toy H: $A$ rare cause of ileus: invagination due to ectopic pancreas. Acta Chir Belg 2008, 108:343-345.

4. Chiang JM, Lin YS: Tumor spectrum of adult intussusception. J Surg Oncol 2008, 98:444-447.

5. Savargaonkar P, Morgenstern N, Bhuiya $T$ : Inflammatory fibroid polyp of the ileum causing intussusception: report of two cases with emphasis on cytologic diagnosis. Diagn Cytopathol 2003, 28:217-22I.

6. Ott DJ, Wu WC, Shiflett DW, Pennell TC: Inflammatory fibroid polyp of the duodenum. Am J Gastroenterol 1980, 73:62-64.

7. Yakan S, Caliskan C, Makay O, Denecli AG, Korkut MA: Intussusception in adults: clinical characteristics, diagnosis and operative strategies. World J Gastroenterol 2009, I 5:1985-1989.

8. Yalamarthi S, Smith RC: Adult intussusception: case reports and review of literature. Postgrad Med J 2005, 81: I74- 177.

9. Karamercan A, Kurukahvecioglu O, Yilmaz TU, Aygencel G, Aytaç B, Sare M: Adult ileal intussusception: an unusual emergency condition. Adv Ther 2006, 23:163-168.

10. Wysocki AP, Taylor G, Windsor JA: Inflammatory fibroid polyps of the duodenum: a review of the literature. Dig Surg 2007, 24:162-168.

II. Daum O, Hes O, Vanecek T, Benes Z, Sima R, Zamecnik M, Mukensnabl P, Hadravska S, Curik R, Michal M: Vanek's tumor (inflammatory fibroid polyp). Report of 18 cases and comparison with three cases of original Vanek's series. Ann Diagn Pathol 2003, 7:337-347.

12. Calabuig-Farinas S, Lopez-Guerrero JA, Ribera MJ, Navarro S, Ramos D, Pellin A, Llombart-Bosch A: Inflammatory fibroid polyp of the small bowel with a mutation in exon 12 of PDGFRalpha. Virchows Arch 2009, 454:327-33I.

13. Korkmaz O, Yilmaz HG, Tacyildiz IH, Akgun Y: Intussusception in adults. Ulus Travma Acil Cerrahi Derg 2009, 15:154-158.

14. Bandyopadhyay PK, Ishaq N, Malik AK, Mahroos S: Inflammatory fibroid polyp of proximal ileum causing recurrent intussusception. Br J Clin Pract 1997, 5 I: I25-I26.

15. Jabar MF, Prasannan S, Gul YA: Adult intussusception secondary to inflammatory polyps. Asian J Surg 2005, 28:58-6I.

16. Sorantin E, Lindbichler F: Management of intussusception. Eur Radiol 2004, I4:146-154. 